\title{
REMOTE SENSING OF WEATHER FOR AVIATION MANAGEMENT
}

\author{
Pravas R. Mahapatra \\ Department of Aerospace Engineering \\ Indian Institute of Science, Bangalore 560012, INDIA \\ Dusan S. Zrnic' \\ NOAA National Severe Storms Laboratory \\ 1313 Halley Circle, Norman, OK 73069 , U.S.A
}

\section{ABSTRACT}

Remote sensing of weather is recognized as an important step to enhance the quality of aviation. In the last two decades important strides have been made in understanding the role of atmospheric phenomena in aviation, and devising instruments and systems for mitigating their disruptive effects. This paper provides a brief summary of some of the main developments. The diversity of the types of atmospheric phenomena that affect aviation makes their remote sensing a challenging task. The Doppler weather radar and its variants have emerged as the mainstay of the evolving aviation weather remote sensing framework. A long range Doppler radar chain is well suited to perform weather detection for en roufe flight operations. For the more dense flight environment of the terminal areas, specialized systems with shorter range are preferable. Emphasis has been put on automation of sensor operation, and the acquisition, processing and dissemination of information.

Kcy Words: Aviation Weather, Aviation Safety, Weather Radars, Air Traffic Control, Doppler Weather Radar.

\section{INTRODUCTION}

Aircraft flight is naturally affected by phenomena occurring in the atmosphere. As aircraft have become bigger, and aviation operations more widespread, damage and disruptions to aviation due to unfavorable weather have also mounted. To minimize the disruptive effects of weather on aviation, it is first necessary to detect such phenomena and estimate their extent and severity from the aviation point of view. Since aviation is an open operation, i.e it occurs over widely spread volumes of space on a global scale, remote sensing methods provide the best way to achieve this goal. Considerable research has been conducted in the recent decades to understand weather effects on aviation. A number of remote sensing systems have also been developed to aid aviation.

\section{WEATHER AND AVIATION}

Air traffic control and management systems around the world aim to maximize the twin objectives of safety and efficiency. Hitherto, the prime focus of air traffic control (ATC) has been to maintain adequate aireraft separation to minimize the possibility of collision. A complex procedural framework, supported by instrumentation and communication, has been built up in most parts of the world to ensure smooth flow of air traffic [1]. The system has been quite effective, making commercial aviation among safest forms of transportation [2].

Still many factors affect aviation adversely. Among these, weather is an important one. Weather has been found to be responsible for a number of serious air crashes. Passenger discomfort due to adverse weather is a matter of fairly common experience. Another effect of weather on aviation is
Table 1 Causes of Airline Delays

\begin{tabular}{|lrc|}
\hline Cause of Delay & $\begin{array}{c}\text { Annual } \\
\text { Delays }\end{array}$ & $\begin{array}{c}\text { Percentage of } \\
\text { Total Delays }\end{array}$ \\
\hline Weather & $2,46,187$ & 70 \\
Terminal Volume & 38,560 & 11 \\
En Route Volume & 49,960 & 12 \\
Closed Runway or Taxiway & 12,809 & 4 \\
Equipment Interruptions & 12,035 & 3 \\
\hline Total & $\mathbf{3 , 5 3 , 5 5 1}$ & $\mathbf{1 0 0}$ \\
\hline
\end{tabular}

to cause flight delays. Table 1 [3] shows that weather factors account for as much as $70 \%$ of all airline delays in the U.S

Proper observation of atmospheric factors affecting aviation is necessary to reduce their harmful effects on aviation. Remote sensing is playing a major role in this task. Remote sensing of aviation weather is a challenging field because of the diversity of the phenomena that affect aviation, and the special needs and constraints of aviation. Aviation, being a highly dynamic operation, requires rapid observations. Further, the weather factors affecting aviation strongly may be different from those that interest the general meteorologist.

Atmospheric phenomena of significance to aviation are of five major types:

1. Motion of Air Masses: Systematic but differential motion of air over a scale that can affect the aircraft's flight path is called windshear. It has been found responsible for many of the weather related accidents. A chief source of windshear is the thunderstorm. The descending shaft of cold air from the core of the storm cell diverges out on approaching the ground Aircraft flying through this divergent field encounter rapid reversal of the wind field which may result in uncorrectable flight path aberrations. A particularly hazardous phenomenon for aviation is the microburst, which produces intense divergence fields (with speeds up to $75 \mathrm{~m} / \mathrm{s}$ ) [4] over highly localized areas (less than $4 \mathrm{~km}$ ). It is also highly transitory in nature, with peak winds lasting only 2-5 minutes. Mesocyclones, tornadoes, gust fronts, cold-warm air fronts, and topographical factors are other sources of windshear.

Turbulence is the phenomenon of random motion of air pockets of different dimensions. Such motion excites various modes in a passing aircraft, and may cause structural damage, passenger discomfort, and/or loss of control.

The ability to sense air velocities is essential for the remote sensing of windshear and turbulence.

2. Hydrometeorological Phenomena: Hydrometeors are particulate matter consisting of different forms of water. Rain, snow and hail are the most common forms. In general their 
presence causes poor visibility. On the ground, they may cause skidding during aircraft landing. Dense rain and hail hampers the combustion process in jet engines, and causes loss of thrust. Impact of large hail can cause physical damage to aircraft's exposed parts and engine blades. Since particulate matter is a good scatterer of EM energy, remote sensing of hydrometeorological phenomena is relatively straightforward.

3. Icing: When aircraft fly through clouds at heights near the freezing altitude, ice accretion may occur over its leading surfaces, altering air flow and adding to the weight of aircraft. The presence of supercooled water at the altitude of interest is an indicator of conditions conducive to icing.

4. Low Visibility: At low altitudes, where much of the terminal area operations like landing and takeoff takes place, adequate visibility is a prime requirement. At the ground level, a frequent visibility-reducing factor is foy. At a somewhat higher level, a chief cause of poor visibility is a lowering of cloud base, i.e. the bottom of cloud columns. At all altitudes, rain, snow and hail may affect visibility seriously.

Different remote sensing methods are necessary for different visibility-reducing factors. Rain, snow and hail can be sensed by their microwave scattering properties, as in a radar. Aerosol type phenomena such as clouds and fog are almost transparent to microwave radars, but can be sensed by optical devices such as the lidar

5. Electrical Phenomena: Atmospheric electricity can have deleterious effects on aircraft. Aircraft passing through regions of strongly charged clouds and strong electric field gradients may encounter [5] or even trigger [6] lightning. Lightning may cause strong stray electrical currents through circuits which may damage semiconductor components, or cause malfunction of on-board instruments and computers. It may also damage the aircraft physically, and cause fire hazards in the presence of fuel vapors.

Lightning activity may be detected remotely in a variety of ways. Its optical flash can be detected within the line of sight, and its powerful broad band electromagnetic emissions can be passively detected at long ranges. By employing suitable antennas, its direction from the observer can also be determined passively. Its position can be determined approximately from the received signal strength, and accurately through triangulation. The column of plasma created by lightning is a microwave scatterer, and can be detected by radar.

\section{REMOTE SENSING OF AVIATION WEATHER}

Although a variety of devices can be used for remotely sensing different aspects of aviation weather, maximum simplicity in system architecture and operation can be achieved by using common instruments for detecting as many types of phenomena as possible. Further, since aviation is a highly dynamic operation, information processing needs to be automated at a high level to minimize delays due to human operators. The instruments used for remote sensing should be compatible with such a system philosophy. Following this logic, radar and radar-type instruments have emerged as the main tools for remote sensing of aviation weather.

\section{WEATHER RADAR IN AVIATION}

A major advantage of radar weather surveillance over in situ instruments is that radar observes the atmosphere at several elevation levels. Thus, it is possible to predict the occurrence of phenomena with potentially damaging effect at or near the ground level by observing precursors that may occur at higher levels. Indeed, precursor observation may be necessary to meet the Federal Aviation Administration (FAA) requirement that a windshear warning must be issued at least one minute prior to the time that an airport will encounter "hazardous" windshear.

There are two distinct phases of aviation operations: the terminal area operations and the en route operations. As weather has significantly different effects on these two phases, the approaches to mitigating these effects are also different for the two phases. For the en route operations the Next Generation Weather Radar (NEXRAD letter designation WSR-88D) is slated to be the primary observing instrument Several of these have been installed in the U.S., with the ultimate number currently projected to be over a hundred. To service the terminal area a Terminal Doppler Weather Radar (TDWR) will be deployed at each of 47 U.S. airports. The new Airport Surveillance Radar (ASR-9) with a dedicated weather channel will fulfill the weather observation roll at many other airports. Some details of the systems are given below.

1. WSR-88D: This is a fully coherent radar operating in the $10 \mathrm{~cm}$ band, with a 1 degree pencil beam. The major units of the system are (Figure 1) the Radar data Acquisition (RDA) Unit, the radar Product Generator (RPG), and the Principal User Processor. The first unit performs the basic radar functions such as the transmission, reception and processing of signals, the second performs the computational functions for generating the radar data products, and the last unit maintains interface with users and provides display and control of data at user locations.The WSR-88D uses highquality full-color displays for primary data products and has powerful software for generating higher level weather products such as precipitation accumulation, identification and parametrization of storms, mesocyclones, divergence, tornadic vortices, turbulence zones and windshear zones.

The WSR-88D has a very high dynamic range and high sensitivity to facilitate weather observation over long ranges $(460 \mathrm{~km}$ for reflectivity and $230 \mathrm{~km}$ for velocity measurement), and with or without precipitation. It also achieves a high level of clutter rejection by using five-pole digital IIR filters with software-controlled notch widths [7] The radar is capable of remote, unattended operation and transmission of raw products to the RPG

2. TDWR: The development of the TDWR was strongly motivated by the requirement of timely and reliable detection of microbursts [8]. Its other primary functions are the detection of gust fronts and the prediction of gust frontal wind shifts, and the estimation and graphic display of storm movements. Other aims of the TDWR are to predict storm movements, estimate turbulence in precipitation areas, detect tornadoes, and to predict the surface impact of microbursts

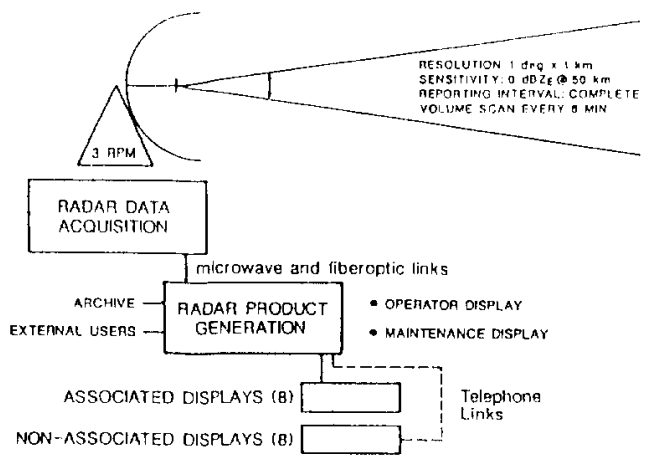

Figure 1 Major subsystems of WSR-88D 
and the initiation of convection leading to the formation of thunderstorm cells. The TDWR will be located within the airport area to effectively observe microburst outflows which are rather shallow, typically having a depth between 300 and $1200 \mathrm{~m}$, with the strongest winds in the lowest $100 \mathrm{~m}$ [9]. To facilitate the measurement of windshear at the lowest altitudes. good ground clutter suppression is a primary design feature of the TDWR. Further, in its 5-minute scan cycle, the lowest level of scan is visited once every minute to provide to comply with the microburst detection criterion.

In contrast with the WSR-88D, the TDWR operates at about 5 $\mathrm{cm}$ of wavelength, which was based on the availability of suitable frequency band. The shorter wavelength has the advantages of lower radio frequency interference, and better signal-to-clutter ratio for a given precipitation intensity. However, it has the disadvantage of higher attenuation rates through heavy rain, which causes errors in the estimation of precipitation in distant parts of heavy weather fields.

The TDWR is also designed for automated operation, and its powerful software makes it user friendly. The air traffic controlters receive the data in alphanumeric format, to be read to pilots. Supervisors in control towers would receive the data in the form of "geographic situation display", which is a color overlay of many different types of wind field and precipitation data on a runway area geographic map.

3. ASR-9. The airport surveillance radars (ASRs), required for primary air traffic control (ATC) function, are located close to the center of the runway complex. Since this is also a vantage point for airport weather surveillance, the latest radar in the series, the ASR-9, has a dedicated weather channel The special advantage of this arrangement is that ASRs are installed at many more airports than the limited number (47) which are slated to have the TDWR

In contrast to a dedicated weather radar (e.g. WSR-88D, TDWR). which have narrow pencil beams scanning at many levels, the ASR has a fan beam scanning at uniform elevation. This difference has a strong bearing on vertical resolution, clutter rejection capability, and signal processing. Also, the ASR is usually located near the center of the runway complex, whereas the optimum site for an airport weather surveillance radar is about $10-12 \mathrm{~km}$ away from that point [10]. The ASR9 achieves an acceptable fusion of the weather and ATC functions in spite of such basic differences between the two roles. The weather channel of ASR-9 provides the ATC personnel with accurate, quantized, clutter-free pictures of the precipitation field which is quantized to six levels specified by the US National Weather Service. The ATC personnel may select and display any two of the six levels.

The ASR-9 uses a unique configuration with two receivers, each receiving signals of a different sense of polarization, to optimize the reception of both target and precipitation echoes simultaneously. The use of a clutter-map-controlled filter bank provides a high degree of resistance to ground clutter. This radar is also capable of unattended operation, with facilities for remote performance monitoring, fault isolation, and control. Over a hundred of these radars are planned to be installed.

The ASR-9 antenna produces two fan beams separated in elevation, and scans in azimuth only at a speed of 12.5 RPM. This produces raw data updates every 5 seconds which is very advantageous for observing fast-changing phenomena. In normal use, the data can be averaged over about half a minute for smoothing.

An optional processing channel in the ASR-9 can automatically detect regions of low-altitude windshear in the presence of precipitation.

\section{WIND PROFILERS}

Wind profilers are radar-like instruments that point upward, and the clear-air echo returned by various layers can be processed to yield information about those layers. By tilting the beam from the vertical and providing discrete or conical scanning, a coherent receiver can estimate the horizontal velocities of the various layers of atmosphere over the profiler. A profile of such velocities can be used to determine the vertical shear, which is also of importance to aviation, especially during takeoff and landing. Profiler data complement data from Doppler radars which provide estimates of horizontal shear.

Wind profilers have been designed to cover various height slabs from a couple of kilometers above the surface to about $20 \mathrm{~km}$, and their operating frequencies lie in the range from $50 \mathrm{MHz}$ to $1 \mathrm{GHz}$. The power, size and cost of profilers increase rapidly with increase in height coverage. As the windshear in the lowest layers of the atmosphere is of utmost importance for aviation, even small profilers (called Boundary Layer Profilers) operating at about $915 \mathrm{MHz}$ can serve as very useful aids for aviation.

\section{CONCLUDWG REMARKS}

Remote sensing of weather is beginning to play a formal and significant role in enhancing the safety and efficiency of aviation. As this process gathers strength over the coming years, the emphasis will be on a systems approach. To cope with the distributed and dynamic nature of aviation, the approach to remote sensing of weather for aviation will emphasize a high degree of automation in the acquisition, processing, and dissemination of weather information, while retaining an adequate level of human control

\section{REFERENCES}

[1] T. S. Perry, and P. Wallich, "A Matter of Margins," IEEE Sipec:nm vol. 23 , pp. 38-49, 1986

[2] M. A. Fischetti, and T. S. Perry, "Our Burdened Skies," IEEE Silectrum, vol. 23, pp. 36-37, 1986.

[3] N. A. Blake, "FAA Engineering Programs for Aviation," Rull. Amer Meteoral. Soc., vol. 69, p. 639-642, 1988.

[4] Fujita, T. T., The Downburst. Chicago: The University of Chicago, 1985 , ch. 2, p. 8

[5] V. Mazur, D. B. Fisher, and J. C. Gerlach, "Lightning Strikes to an Airplane in a Thunderstom," I. Aircraft, vol. 21, pp. 607-611, 1984

[6] D. R. Fitzgerald, "Probable Aircraft Triggering of Lightning in Certain Thunderstonns," Mon. Wea. Rev., vol. 95, pp. 835-842, 1967.

[7] W. H. Heiss, D. L. McGrew, and D. S. Sirmans, "Nexrad: Next Generation Weather Radar (WSR-88D)," Microwave J., vol. 33, pp. 7998. 1990

[8] D. Turnbull, J. McCarthy, J. Evans, and D. S. Zmic', "The FAA Terminal Doppler Weather Radar Program," in "Yoc. Thirl Int7 Conf. on the Aviation Weather System. Analieim, Califomia, 1989, pp. 414-419

[9] J. W. Wilson, R. D. Roberts, C. Kessinger, and J. McCarthy, Wind Shear Detection," J. Clim. Appl. Meteorol vol. 23. pp. 898.915, 1984.

[I0] P. R. Mahapatra, D. S. Znic', and R. J. Doviak, "Optimum String of NEXRAD to Detect Hazardous Weather at Airports," J. Aircrufi, vol. 20 pp. 363-371, 1983.

[11] W. L. Eklund, D. A. carter, and B. B. Balsley, " A UHF Wind Profiler for the Boundary Layer: Brief description and Initial results," Atm. Oceunic Tech., vol. 5, pp. 432-44l, 1988. 